\title{
Protein Inhibitor of Activated STAT (PIAS) Negatively Regulates the JAK/STAT Pathway by Inhibiting STAT Phosphorylation and Translocation
}

\author{
Guo-Juan Niu ${ }^{1}$, Ji-Dong Xu ${ }^{1}$, Wen-Jie Yuann ${ }^{1}$, Jie-Jie Sun ${ }^{1}$, Ming-Chong Yang ${ }^{1}$, \\ Zhong-Hua He ${ }^{1}$, Xiao-Fan Zhao ${ }^{1}$ and Jin-Xing Wang ${ }^{1,2 *}$
}

${ }^{1}$ Shandong Provincial Key Laboratory of Animal Cells and Developmental Biology, School of Life Science, Shandong University, Qingdao, China, ${ }^{2}$ State Key Laboratory of Microbial Technology, Shandong University, Qingdao, China

\section{OPEN ACCESS}

Edited by:

Timothy B. Niewold,

New York University, United States

Reviewed by:

Nina Ivanovska,

Institute of Microbiology (BAS),

Bulgaria

Junji Xing,

Houston Methodist Research Institute, United States

*Correspondence: Jin-Xing Wang

jxwang@sdu.edu.cn

Specialty section:

This article was submitted to

Molecular Innate Immunity,

a section of the journal

Frontiers in Immunology

Received: 28 April 2018

Accepted: 26 September 2018

Published: 26 October 2018

Citation:

Niu G-J, Xu J-D, Yuan W-J, Sun J-J, Yang $M-C, H e Z-H$, Zhao X-F and Wang J-X (2018) Protein Inhibitor of

Activated STAT (PIAS) Negatively Regulates the JAK/STAT Pathway by Inhibiting STAT Phosphorylation and

Translocation.

Front. Immunol. 9:2392.

doi: 10.3389/fimmu.2018.02392
Protein inhibitor of activated STAT (PIAS) proteins are activation-suppressing proteins for signal transducer and activator of transcription (STAT), which involves gene transcriptional regulation. The inhibitory mechanism of PIAS proteins in the Janus kinase (JAK)/STAT signaling pathway has been well studied in mammals and Drosophila. However, the roles of PIAS in crustaceans are unclear. In the present study, we identified PIAS in kuruma shrimp Marsupenaeus japonicus and found that its relative expression could be induced by Vibrio anguillarum stimulation. To explore the function of PIAS in shrimp infected with $V$. anguillarum, we performed an RNA interference assay. After knockdown of PIAS expression in shrimp subjected to $V$. anguillarum infection, bacterial clearance was enhanced and the survival rate increased compared with those in the control shrimp (dsGFP injection). Simultaneously, the expression levels of antimicrobial peptides (AMPs), including anti-lipopolysaccharide factor (ALF) A1, C1, C2, and Crul-1, increased. Further study revealed that knockdown of PIAS also enhanced STAT phosphorylation and translocation. Pulldown assay indicated that PIAS interacts with activated STAT in shrimp. In conclusion, PIAS negatively regulates JAK/STAT signaling by inhibiting the phosphorylation and translocation of STAT through the interaction between PIAS and STAT, which leads to the reduction of AMP expression in shrimp. Our results revealed a new mechanism of PIAS-mediated gene regulation of the STAT signal pathway.

Keywords: protein inhibitor of activated STAT, signal transducer and activator of transcription, signaling pathway, antimicrobial peptide, Marsupenaeus japonicus

\section{INTRODUCTION}

The protein inhibitor of activated STAT (PIAS) family was identified an inhibitor of signal transducer and activator of transcription (STAT) acting on the Janus kinase (JAK)/STAT signaling pathway $(1,2)$. The PIAS family in mammals has at least five members: PIAS1, PIASx $\alpha$, PIASx $\beta$, PIAS3, and PIASy. All the PIAS proteins are highly conserved and have common structural features. They have an N-terminal SAFA/B, Acinus and PIAS (SAP) domain (3), a Pro-Ile-Asn-Ile-Thr (PINIT) motif (4), a RING finger-like Zinc binding domain (RLD) (5), an acidic amino acid domain (AD) $(6,7)$, and C-terminal Ser/Thr amino acids enriched region (S/T). The SAP 
domain is involved in sequence- or structure-specific DNA binding (8). The PINIT motif, a highly conserved region of PIAS proteins, is involved in the nuclear retention (4). The RLD is required for the SUMO-E3-ligase activity of PIAS proteins and might be involved in the interaction with other proteins (9). A putative SUMO1-interaction motif (SIM) is present in the AD (10). The C-terminal S/T-rich region is the least conserved and its function remains to be defined.

PIAS has a variety of vital functions, including cell proliferation (11), cell differentiation, cell apoptosis, tumor development, and the immune response (12). The PIAS family can bind to many transcription factors in signaling pathways such as the STAT and nuclear factor kappa B (NF- $\mathrm{B})$ pathways (13, 14). By interacting with transcription factors or transcriptional coactivators, PIAS could regulate the activity of downstream genes (15).

It has been reported that PIAS1 plays an important role in the negative regulation of the JAK/STAT pathway (16). PIAS proteins inhibit transcription in four ways: closing off the DNA binding activity of transcription factors (2), recruiting cofactor proteins (17), promoting the SUMOylation of transcription factors (18), and sequestering transcription factors in distinct subnuclear structures (19). However, there is little research on the involvement of PIAS in the response to the invasion of pathogenic microorganisms, especially in crustaceans. In the present study, we identified a PIAS cDNA from the kuruma shrimp (Marsupenaeus japonicus), and designated its encoded protein as MjPIAS. MjPIAS expression was upregulated in shrimp challenged with Vibio anguillarum. To analyze the function of MjPIAS in shrimp immunity, RNA interference (RNAi) was performed. After knockdown of MjPIAS and $V$. anguillarum infection, the bacterial number in shrimp declined and the shrimp survival rate increased. The possible mechanism of MjPIAS in antibacterial immunity was further studied.

\section{MATERIALS AND METHODS}

\section{Immune Challenge and Tissue Collection}

M. japonicus shrimp (weighing 9-11 g/shrimp) were purchased from the seafood market in Jinan, Shandong Province, China. The shrimp were kept at $24^{\circ} \mathrm{C}$ for $48 \mathrm{~h}$ in laboratory tanks at a salinity of $26 \%$ o $(\mathrm{w} / \mathrm{v})$ to acclimatize them to the environment. $V$. anguillarum $\left(2 \times 10^{8}\right.$ cells $)$ was injected into the abdomen to infect the shrimp. The same volume of PBS $(140 \mathrm{mM} \mathrm{NaCl}$, $2.7 \mathrm{mM} \mathrm{KCl}, 10 \mathrm{mM} \mathrm{Na} 2 \mathrm{HPO} 4$, and $1.8 \mathrm{mM} \mathrm{KH}_{2} \mathrm{PO}$, $\mathrm{pH}$ 7.4) was injected into the control groups. Hemocytes were collected into anticoagulant buffer $(450 \mathrm{mM} \mathrm{NaCl}, 10 \mathrm{mM} \mathrm{KCl}, 10 \mathrm{mM}$ EDTA, $100 \mathrm{mM}$ HEPES, $\mathrm{pH}$ 7.45) after centrifugation at 800 $\times \mathrm{g}$ for $6 \mathrm{~min}$ at $4^{\circ} \mathrm{C}$. Other tissues (heart, hepatopancreas, grills, stomach, and intestine) were homogenized separately in TRIpure Reagent (Bioteke, Beijing, China) for RNA extraction or in radio-immunoprecipitation assay (RIPA) buffer (50 mM Tris$\mathrm{HCl}, 150 \mathrm{mM} \mathrm{NaCl}, 0.1 \%$ SDS, 0.5\% Nonidet P-40, 1 mM EDTA, $0.5 \mathrm{mM}$ PMSF, $\mathrm{pH}$ 7.5) for protein extraction. The supernatant was obtained by centrifugation at $12,000 \times \mathrm{g}$ for $10 \mathrm{~min}$ at $4^{\circ} \mathrm{C}$.
TABLE 1 | Sequences of the primers used in this study.

\begin{tabular}{|c|c|}
\hline Primer & Sequence $\left(5^{\prime}-3^{\prime}\right)$ \\
\hline Smart F & TACGGCTGCGAGAAGACGACAGAAGGG \\
\hline Oligo anchorR & GACCACGCGTATCGATGTCGACT16(A/C/G) \\
\hline MjPIAS-RT-F & ATCGCCACCACTTCCTTG \\
\hline MjPIAS-RT-R & CCTCTGATTTCCGCTTCTC \\
\hline MjPIAS-RLD-EXF & TACTCAGGATCCCTGACCTCAGATGAC \\
\hline MjPIAS-RLD-EXR & TACTCACTCGAGGAAGTATCCATCAAT \\
\hline Actin-RT-F & AGTAGCCGCCCTGGTTGTAGAC \\
\hline Actin-RT-R & TTCTCCATGTCGTCCCAGT \\
\hline MjPIAS-Ri-F & GCGTAATACGACTCACTATAGGAAGTGATCTGCTTAGACA \\
\hline MjPIAS-Ri-R & GCGTAATACGACTCACTATAGGCAAATGCTGCAACCATCC \\
\hline GFP-RNAi-F & $\begin{array}{l}\text { TAATACGACTCACTATAGGGGGGTGGTCCCAATTCTCGTGG } \\
\text { AAC }\end{array}$ \\
\hline GFP-RNAi-R & TAATACGACTCACTATAGGGCTTGTACAGCTCGTCCATGC \\
\hline ALF-A1-RT-F & CTGGTCGGTITCCTGGTGGC \\
\hline ALF-A1-RT-R & CCAACCTGGGCACCACATACTG \\
\hline ALF-C1-RT-F & CGCTTCAAGGGTCGGATGTG \\
\hline ALF-C1-RT-R & CGAGCCTCTTCCTCCGTGATG \\
\hline ALF-C2-RF-F & TCCTGGTGGTGGCAGTGGCT \\
\hline ALF-C2-RF-R & TGCGGGTCTCGGCTTCTCCT \\
\hline Crul-1-RT-F & TGCTCAGAACTCCСТCCACC \\
\hline Crul-1-RT-R & TTGAATCAGCCCATCGTCG \\
\hline
\end{tabular}

\section{RNA Extraction and cDNA Reverse Transcription}

Total RNA was first extracted from the six tissues (five organs plus the hemocytes) using the Trizol reagent and then reverse transcribed to cDNA according to the SMART cDNA reverse transcription kit (M-MLV version; Takara, Dalian, China) using the primers Smart F and oligo anchorR (Table 1).

\section{cDNA Cloning of MjPIAS and Phylogenetic Analysis}

The sequence of MjPIAS was obtained by transcriptomic sequencing of hemocytes, and confirmed by replication with reverse transcription PCR (RT-PCR) using specific primers (Table 1). The EXPASY translation tool was used to analyze the deduced amino acid sequence (http://web.expasy.org/translate/). The domain architecture was predicted using SMART (http:// smart.embl.de/). The sequences of PIAS from other species were collected from NCBI GenBank (http://www.ncbi.nlm.nih.gov/ genbank/). A phylogenetic tree was constructed using MEGA version 5.0 .

\section{Tissue Distribution and Expression Profile}

The tissue distribution of MjPIAS was determined using semiquantitative RT-PCR with primers MjPIAS-RT-F and MjPIASRT-R (Table 1). The actin mRNA was amplified using primers Actin-RT-F and Actin-RT-R as an internal control. The RT-PCR procedure was performed as follows: $94^{\circ} \mathrm{C}$ for $3 \mathrm{~min} ; 26$ cycles of $94^{\circ} \mathrm{C}$ for $20 \mathrm{~s}, 54^{\circ} \mathrm{C}$ for $20 \mathrm{~s}, 72^{\circ} \mathrm{C}$ for $20 \mathrm{~s}$; and a final step of $72^{\circ} \mathrm{C}$ for $10 \mathrm{~min}$. The expression profile was further assessed 
using quantitative real-time PCR (qPCR) as follows: $94^{\circ} \mathrm{C}$ for $10 \mathrm{~min}, 40$ cycles of $94^{\circ} \mathrm{C}$ for $15 \mathrm{~s}$ and $60^{\circ} \mathrm{C}$ for $1 \mathrm{~min}$; followed by reading at $78^{\circ} \mathrm{C}$ for $2 \mathrm{~s}$. Each experiment was repeated three times and results were calculated using the $2^{-\Delta \Delta \mathrm{Ct}}$ method. An unpaired $t$-test was used for statistical analysis and a significant difference was accepted at $p<0.05$.

\section{RNA Interference and Bacterial Clearance Assay}

Double-stranded RNA ( $d s M j P I A S)$ was produced to knockdown the expression of MjPIAS. The PIAS fragment was amplified using primers MjPIAS-Ri-F and MjPIAS-Ri-R, and then used to produce the dsRNA via T7 RNA polymerase (Fermentas, Burlington, Canada). The green fluorescent protein (GFP) was used as a control to synthesis GFP dsRNA. DsRNA (30 $\mu \mathrm{g})$ was injected into shrimp and an additional $30 \mu \mathrm{g}$ dsRNA dose was injected $24 \mathrm{~h}$ later. Interference effects were detected at $48 \mathrm{~h}$ using qRT-PCR following $V$. anguillarum challenge (2 $\times 10^{8}$ cells). Bacterial clearance assays were performed $3 \mathrm{~h}$ after $V$. anguillarum injection. The shrimp cell-free hemolymph was collected and gradient diluted to 200-fold. The diluted hemolymph was smeared onto 2216E-agar culture medium and the number of bacterial colonies was counted on the second day.

\section{Survival Rate}

To investigate the effect of PIAS in vivo, a survival rate assay was performed after RNAi of the PIAS gene following $V$. anguillarum challenge $\left(30 \mu \mathrm{l}, 2 \times 10^{8}\right.$ cells $)$ at 48 host dsRNA injection; the $d s G F P$-injection group served as the control. The number of dead shrimp was counted every half day, and the cumulative survival rates were calculated using GraphPad Prism 5.0. The experiment was repeated three times.

\section{Immunocytochemical Analysis to Detect the STAT Subcellular Location in Hemocytes}

To detect whether PIAS inhibits STAT transcriptional activity in hemocytes, we performed immunocytochemistry. $V$. anguillarum $\left(2 \times 10^{8}\right.$ cells $)$ was injected into shrimp after knockdown of MjPIAS for $48 \mathrm{~h}$. Hemocytes were collected $3 \mathrm{~h}$ post infection and spread on a glass slide. Immunocytochemistry was performed following a previously described method (20) with an anti-STAT antibody (prepared in our laboratory) and an anti-p-STAT antibody (Abcam, San Francisco, USA) (21). All glass slides were observed under a fluorescence microscope (Olympus BX51, Tokyo, Japan).

\section{Western Blotting}

The hemolymph was extracted into anticoagulant buffer and centrifuged at $800 \times \mathrm{g}$ for $6 \mathrm{~min}$ at $4^{\circ} \mathrm{C}$ for hemocyte collection, which were resuspended in RIPA buffer. Each sample was separated by $12.5 \%$ SDS-PAGE and transferred onto a nitrocellulose membrane. After blocking with 3\% non-fat milk in Tris-buffered saline (TBS) (150 mM NaCl, 3 mM EDTA, $50 \mathrm{mM}$ Tris- $\mathrm{HCl}, \mathrm{pH} 8.0$ ) for $1 \mathrm{~h}$, the membrane was incubated with antiMjSTAT (1/200 diluted in 3\% blocking milk solution) overnight at $4^{\circ} \mathrm{C}$. The membrane was then washed three times with TBST buffer (150 mM NaCl, $3 \mathrm{mM}$ EDTA, 0.1\% Tween-20, $50 \mathrm{mM}$ Tris- $\mathrm{HCl}, \mathrm{pH} 8.0)$ and incubated with horseradish peroxidase (HRP)-conjugated goat anti-rabbit antibody (1/10,000 diluted in 3\% blocking milk solution) (ZSGB Bio, Beijing, China) for $3 \mathrm{~h}$ at room temperature. After washing with TBST three times and with TBS three times, the immunoreactive proteins on the membrane were visualized using reaction media ( $1 \mathrm{ml} 4$-chloro1-naphthol, $6 \mu \mathrm{H} \mathrm{H}_{2} \mathrm{O}_{2}, 9 \mathrm{ml}$ TBS) in the dark.

\section{Protein Recombinant Expression and Purification}

MjPIAS-RLD fragments were amplified using specific primers $M j$ PIAS-RLD-EXF/R. Then the fragments and pGEX4T-1 plasmid were digested with the same restriction enzymes (BamHI and XhoI). Afterwards, the fragments were subcloned into pGEX4T-1 plasmid. The recombinant plasmids were transformed into Escherichia coli Rosseta (DE3) cells for expression with $0.5 \mathrm{mM}$ isopropyl- $\beta$-D-thiogalactopyranoside (IPTG). Soluble MjPIAS-RLD proteins were purified using GSTBind resin (GenScript, Nanjing, China) affinity chromatography.

The His-tagged MjSTAT plasmid (pET-32a/MjSTAT) in E. coli constructed in our laboratory before was used for MjSTAT expression. MjSTAT expressed as inclusion bodies. Buffer A (50 mM Tris-HCl, 5 mM EDTA, pH 8.0) and Buffer B (50 mM Tris- $\mathrm{HCl}, 5 \mathrm{mM}$ EDTA, $2 \mathrm{M}$ urea, $\mathrm{pH} 8.0$ ) reagents were used for washing the inclusion bodies. Then the inclusion bodies were dissolved in denaturing solution $(0.1 \mathrm{M}$ Tris- $\mathrm{HCl}, 10 \mathrm{mM}$ DL-Dithiothreitol, $8 \mathrm{M}$ urea) and refolded in TBS buffer for purification and pull-down experiment.

\section{Pull-Down Assay}

GST-tagged MjPIAS-RLD (200 $\mu \mathrm{g})$ was incubated with Histagged $M j S T A T$ (with a $1: 1$ ratio) at $4^{\circ} \mathrm{C}$ overnight. Then the GST•Bind resin $(50 \mu \mathrm{l})$ was added and incubated for another $45 \mathrm{~min}$. After washing with PBS five times, elution buffer $(10 \mathrm{mM}$ reduced glutathione, $50 \mathrm{mM}$ Tris- $\mathrm{HCl}, \mathrm{pH}$ 8.0) was added for elute out the bound proteins. The mixture was analyzed by SDS-PAGE.

We further use the recombinant MjPIAS to pull down native STAT in shrimp. Shrimp was challenged by V. anguillarum for $3 \mathrm{~h}$ and hemocytes were extracted for protein extraction. GST-tagged MjPIAS-RLD proteins $(200 \mu \mathrm{g})$ were incubated with natural protein (homogenate of hemocytes, $1 \mathrm{mg}$ ) at $4^{\circ} \mathrm{C}$ overnight. The following steps are the same as above. The resulting mixture was separated by SDS-PAGE, and then transferred onto a nitrocellulose membrane for Western blotting with anti-STAT. GST proteins served as control.

\section{Statistical Methods}

The data are presented as the mean \pm SD derived from at least three independent tests. The difference was determined by oneway ANOVA, followed student $t$-test. A significant difference was accepted at $p<0.05$.

\section{Ethics Statement}

All animal-involving experiments of this study were approved by the Ethics Committee of School of Life Sciences, Shandong University, and all efforts were made to minimize suffering. 


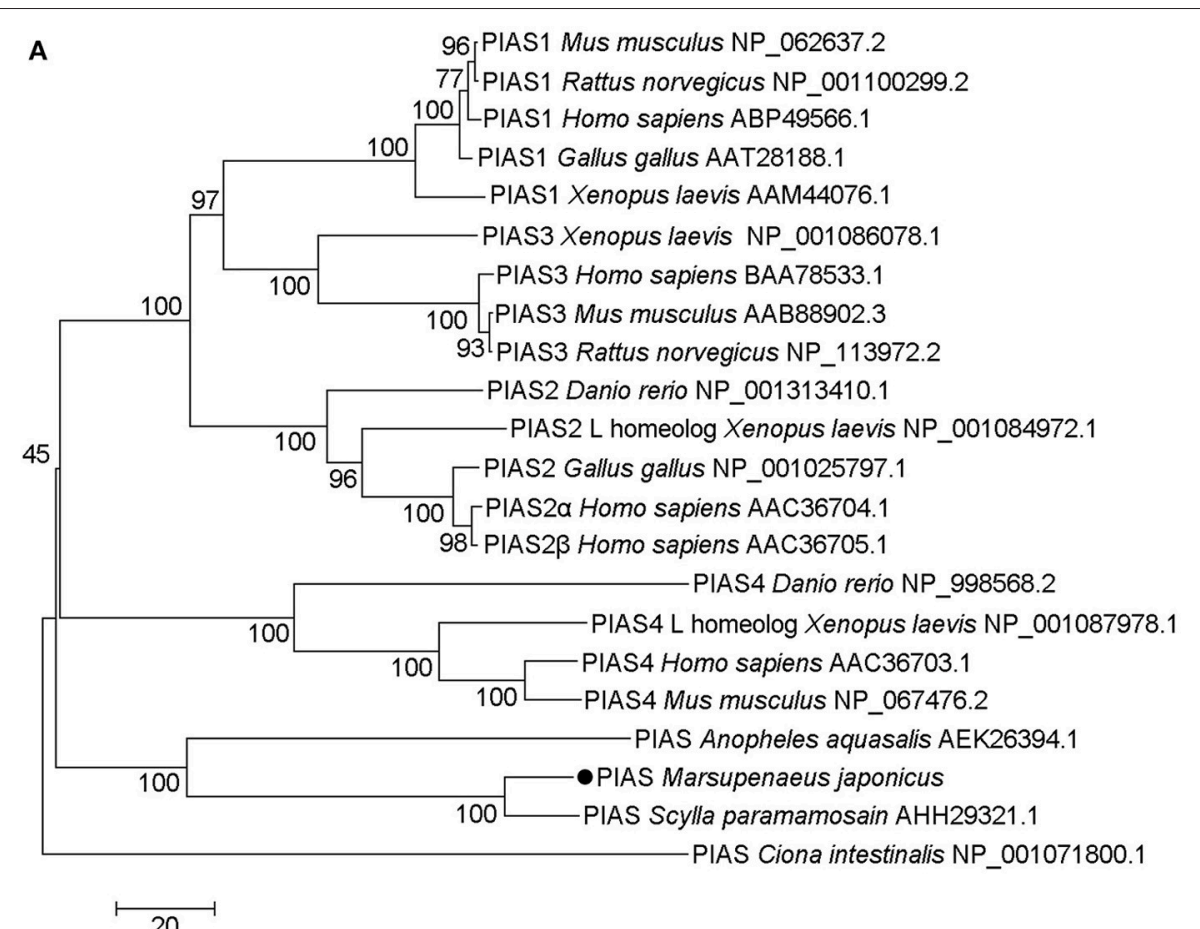

B

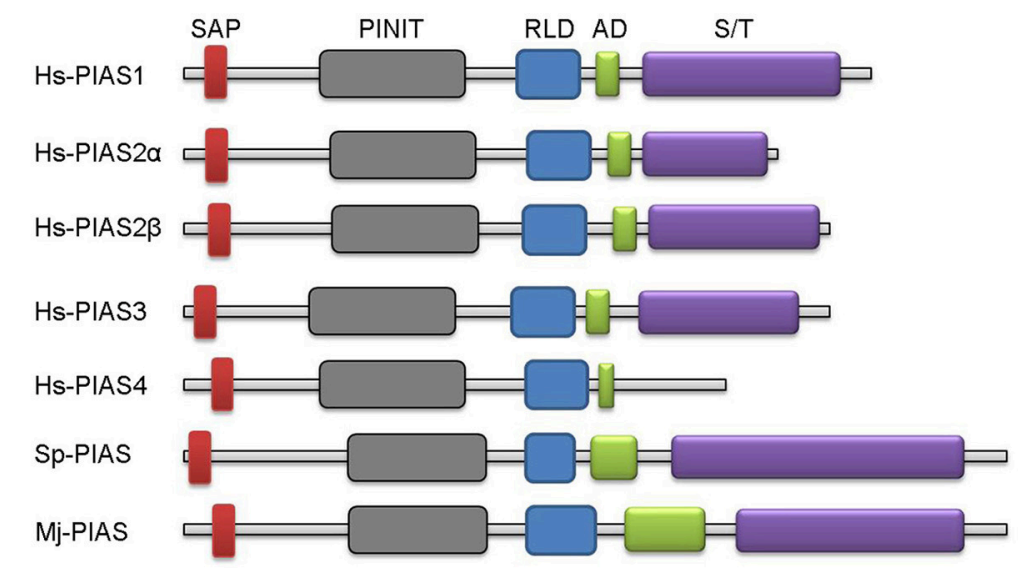

FIGURE 1 | Phylogenetic tree and domain architectures of PIAS from shrimp and other species. (A) Phylogenetic tree of PIAS proteins. The full-length amino acid sequences of PIAS proteins from different species were collected from GenBank and the neighbor-joining phylogenetic tree was constructed using MEGA version 5.0 software. The shrimp PIAS is marked with a dot. The scale bar is shown to indicate the branch length. (B) Domain architectures of PIAS proteins. Hs, Homo sapiens; Sp, Scylla paramamosain; Mj, Marsupenaeus japonicus. Hs-PIAS1, ABP49566.1; Hs-PIAS2 $\alpha$, AAC36704.1; Hs-PIAS2 $\beta$, AAC36705.1; Hs-PIAS3, BAA78533.1; Hs-PIAS4, AAC36703.1; Sp-PIAS, AHH29321.1.

\section{RESULTS}

\section{Bioinformatic Analysis of MjPIAS}

We obtained the full-length cDNA sequence of MjPIAS from M. japonicas (GenBank accession no. MH238442). It contains a SAP, PINIT, RLD, highly acidic region domain (AD), and S/T domains. Phylogenetic analysis revealed that PIAS from $M$. japonicas is closely related to that from Scylla paramamosain (Figure 1A). We also analyzed the domain architecture of PIAS proteins from different species and found that they have the similar domains (Figure 1B), including the SAP domain, which is located at the N-terminus of PIAS proteins, the PINIT domain, an RLD, an $\mathrm{AD}$, and an $\mathrm{S} / \mathrm{T}$ domain in the $\mathrm{C}$-terminal region of the PIAS proteins.

\section{MjPIAS Was Upregulated in Shrimp When Challenged by Bacteria}

We used RT-PCR to analyze the distribution of MjPIAS in different tissues at RNA level. MjPIAS mRNA was expressed in 
A

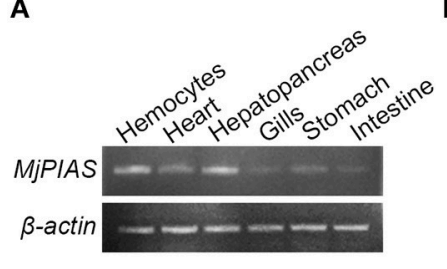

B

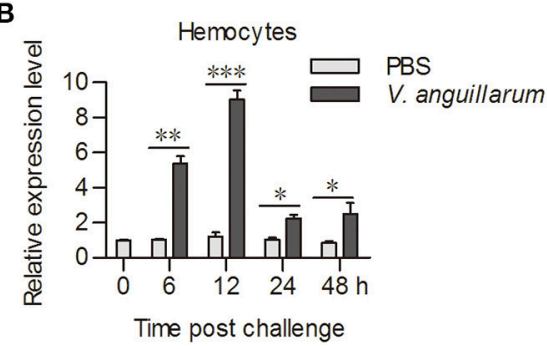

C

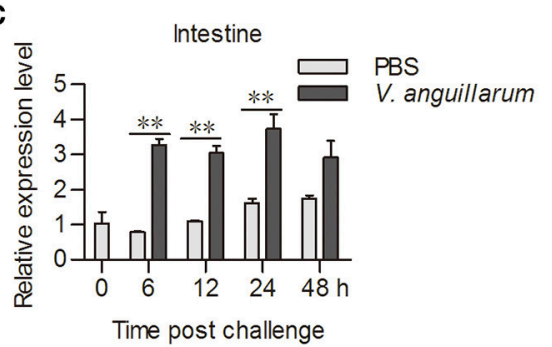

FIGURE 2 | MjPIAS was upregulated in shrimp after $V$. anguillarum challenge. (A) Semi-quantitative RT-PCR analysis of PIAS transcription in different tissues. beta-Actin was used as the control. (B,C) Temporal expression patterns of MjPIAS in hemocytes (B) and intestines (C) of shrimp after injection of $V$. anguillarum. PBS was used as the control. Three repeats were performed and the data were analyzed using an unpaired $t$-test. The asterisks indicate significant differences $v s$. the control $\left({ }^{\star} p<0.05,{ }^{\star \star} p<0.01,{ }^{\star \star \star} p<0.001\right)$.
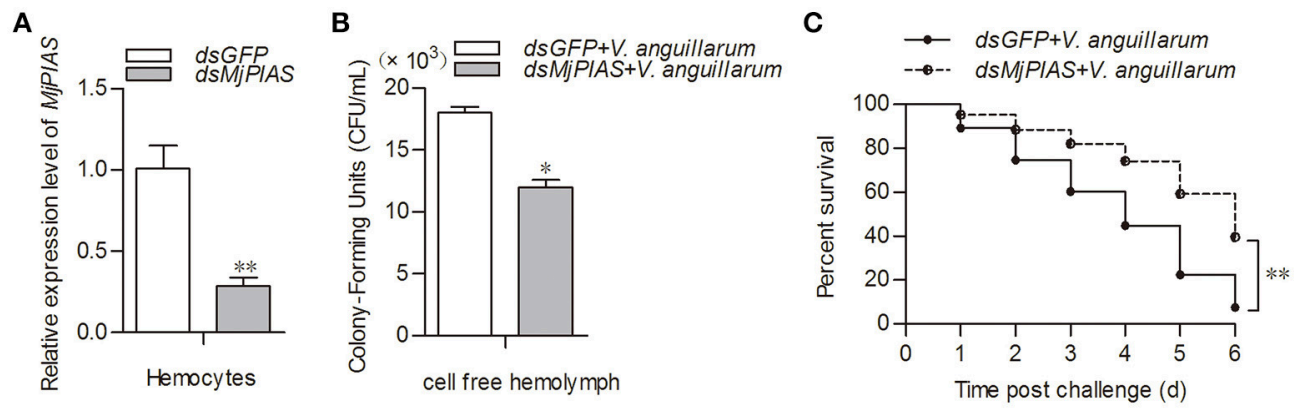

FIGURE 3 | Knockdown of MjPIAS in shrimp facilitated antibacterial immunity in shrimp. (A) Efficiency of MjPIAS RNA interference was analyzed using qRT-PCR. (B) Bacterial clearance was detected after $V$. anguillarum challenge in the dsGFP and dsMjPIAS injection groups. (C) Survival rates of MjPIAS-knockdown shrimp and the dsGFP injection group. The dsRNA was injected into the different groups, followed by injection of $V$. anguillarum at $48 \mathrm{~h}$ post $d s R N A$ injection. The data were analyzed using the unpaired $t$-test. The asterisks indicate significant differences between the dsGFP and $d s M j P I A S$ injection groups $\left({ }^{*} P<0.05\right.$, $\left.{ }^{\star \star} p<0.01\right)$.
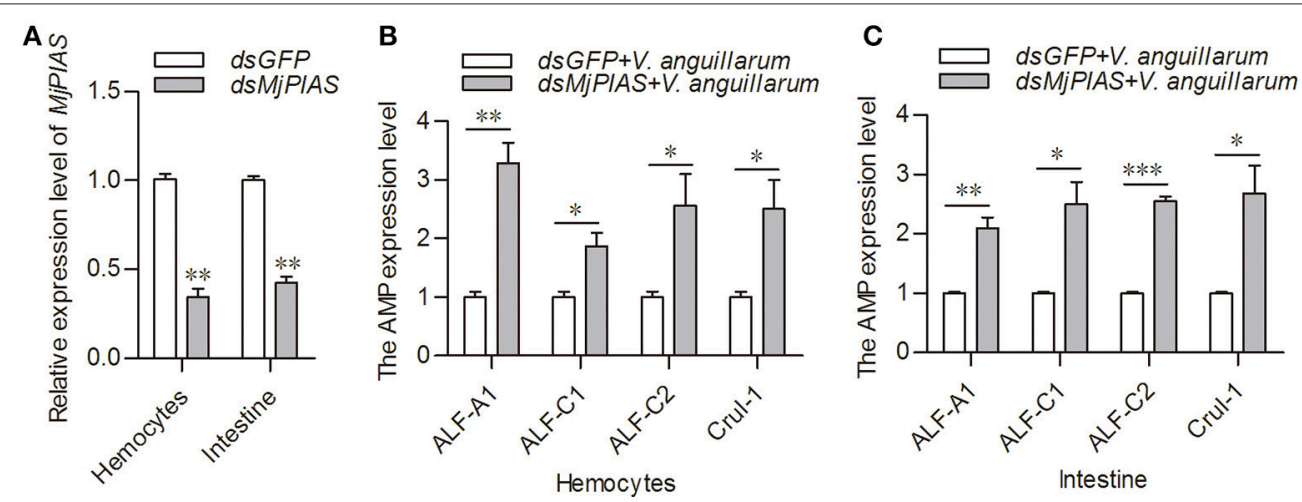

FIGURE 4 | Expression of antimicrobial peptides was increased in the MjPIAS-knockdown shrimp. (A) Efficiency of MjPIAS RNAi. (B,C) After the injection of dsRNA for $48 \mathrm{~h}$, bacterial inoculation was performed and qRT-PCR was used to detect expression of four AMPs (ALF-A1, ALF-C1, ALF-C2, and Crul-1). Three repeats were performed and the data were analyzed using the unpaired $t$-test. The asterisks indicate significant differences between the RNAi and control groups $\left({ }^{\star} p<0.05\right.$,

$\left.{ }^{\star *} p<0.01,{ }^{* * *} p<0.001\right)$.

hemocytes and in all five tested organs (heart, hepatopancreas, gills, stomach, and intestine), with high expression in the hemocytes and hepatopancreas (Figure 2A). We infected shrimp with $V$. anguillarum and extracted the RNA of hemocytes and intestines at different time points. The expression profiles were detected using qRT-PCR. The result showed that MjPIAS expression was significantly upregulated from 6 to $48 \mathrm{~h}$ post bacterial injection, and reached its highest level at $12 \mathrm{~h}$ in the hemocytes (Figure 2B). The high expression of MjPIAS in the intestines continued from 6 to $24 \mathrm{~h}$ (Figure 2C). These results 
A

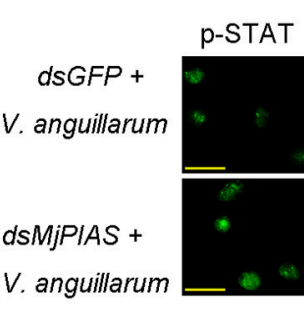

D

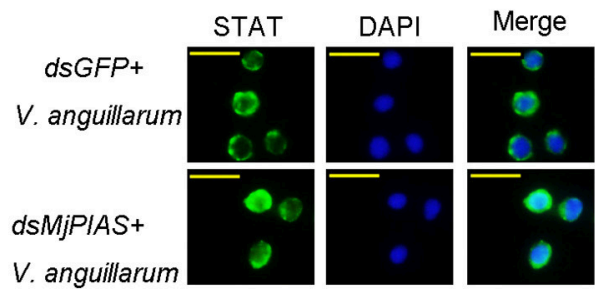

$\mathbf{F}$

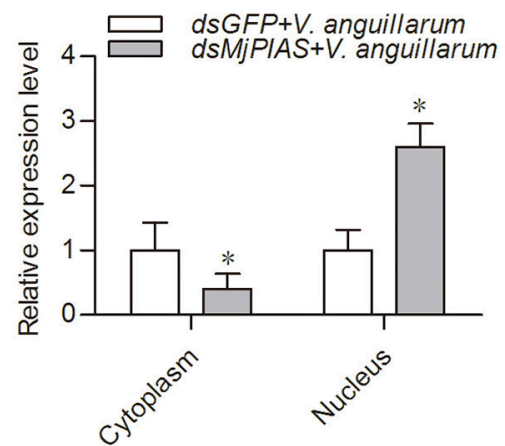

H

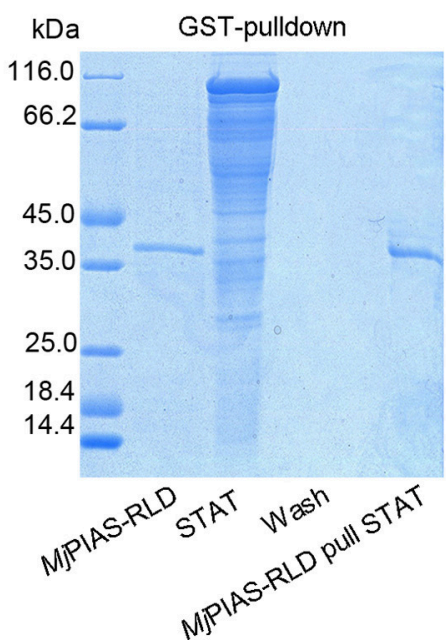

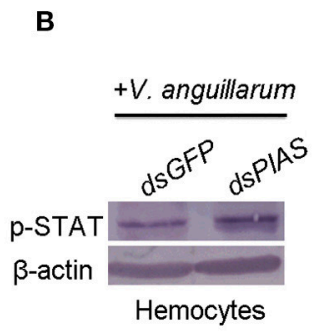

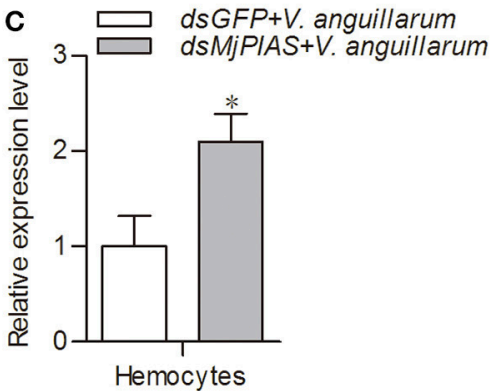

E

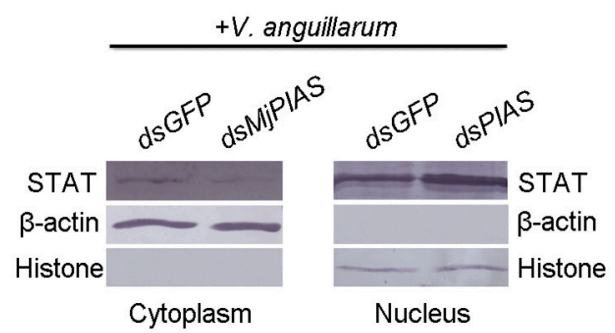

G
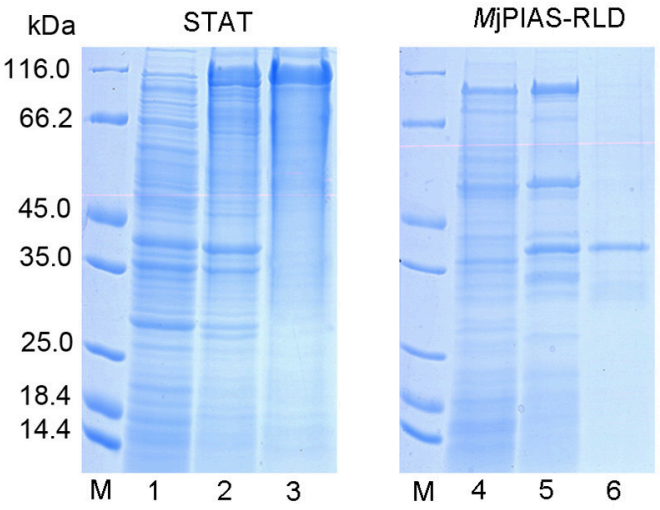

I
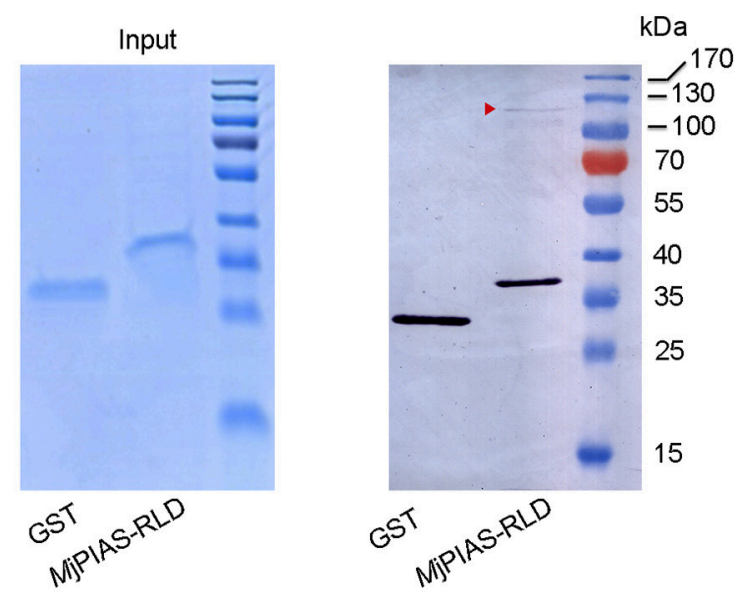

FIGURE 5 | PIAS knockdown promotes STAT translocation and phosphorylation in hemocytes. (A) An immunocytochemical assay was performed to detect the phosphorylated (p)-STAT in the hemocytes of MjPIAS-RNAi shrimp. (B) Proteins were extracted from hemocytes to detect the STAT subcellular location in 
FIGURE 5 | MiPIAS-knockdown and control shrimp using western blotting. (C) Statistical analysis of the western blotting results shown in (B). (D) Immunocytochemical assay to detect STAT translocation in dsRNA-injection shrimp followed V. anguillarum injection. (E) Total cytoplasmic and nuclear proteins were extracted from hemocytes of MjPIAS-RNAi shrimp and the control group, respectively. STAT was detected by western blotting using anti-STAT antibodies. (F) Statistical analysis of the western blotting results shown in (E) ( $\left.{ }^{*} p<0.05\right)$. (G) Recombinant expression and purification of STAT and MjPIAS-RLD. Lane M. Protein standards; Lane 1, total proteins from E. coli with pET-32a/STAT without IPTG induction; lane 2, total proteins from the E. coli with IPTG induction; lane 3, purified recombinant STAT; Lane 4, total proteins from E. coli with pGEX4T1-MjPIAS-RLD without IPTG induction; lane 5, total proteins from the E. coli with IPTG induction; lane 6, purified recombinant MjPIAS-RLD. (H) The interaction of rMjPIAS-RLD with rMjSTAT analyzed using GST-Pulldown assay. (I) Interaction between MjPIAS-RLD with activated STAT from hemocytes of shrimp challenged by $V$. anguillarum. Same amount of proteins of GST and GST-tagged MjPIAS-RLD were shown at the input picture (left). The recombinant proteins could interact with activated STAT was analyzed using western blotting. The red triangle shows the STAT.

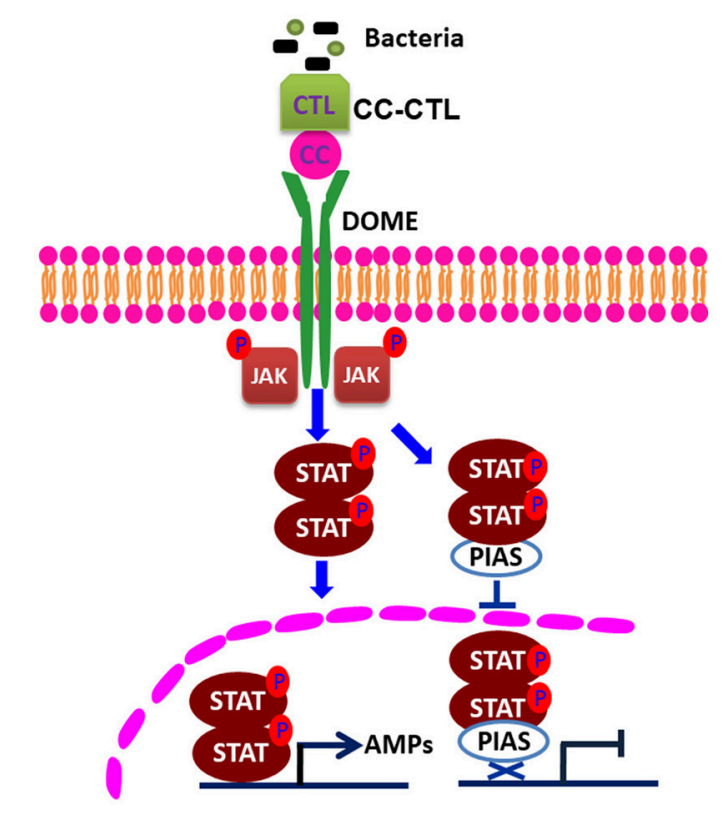

FIGURE 6 | Schematic representation of the mechanism of action of PIAS in the regulation of the STAT signaling pathway. C-type lectin, with CTL and CC domains, recognizes bacteria and interacts with Domelee, and the JAK/STAT signaling pathway is activated. JAK phosphorylates STAT. The phosphorylated STAT enters the nucleus and binds to the promoters of AMP genes to regulate their transcriptions (21). PIAS negatively regulates STAT by inhibiting STAT phosphorylation and nuclear translocation in the JAK/STAT signaling pathway.

suggested that MjPIAS might be associated with antibacterial immunity in shrimp.

\section{PIAS Is Involved in Antibacterial Immunity}

To study the function of MjPIAS, we performed an RNA interference assay to knockdown MjPIAS expression in shrimp. Following $V$. anguillarum infection, we detected the bacterial number in vivo and the shrimp survival rate. MjPIAS expression was successfully knocked down in hemocytes at $48 \mathrm{~h}$ after the injection of $d s M j P I A S$ (Figure 3A). The number of colony-forming units (CFUs) was significantly reduced in the $d s P I A S$ group compared with that in the $d s G F P$ injection group (Figure 3B). Meanwhile, the survival rate of MjPIASknockdown-shrimp was significantly higher than that of the $d s G F P$ injection group (Figure 3C). These results suggested that knockdown of MjPIAS enhanced the shrimp's antibacterial ability. In other words, MjPIAS inhibits the antibacterial ability of shrimp.

\section{MjPIAS Inhibits the Expression of AMP Genes}

The initial description of the function for PIAS proteins was as negative regulators of STATs (22). In our previous study, we showed that activation of the JAK/STAT pathway resulted in AMPs expression (21). To explore whether the antibacterial inhibition ability of $M j$ PIAS is caused by the negative regulation of STAT in shrimp, we detect the expression levels of four AMPs (ALF-A1, ALF-C1, ALF-C2, and CruI-1) that are regulated by the JAK/STAT pathway (21) in MjPIAS-knockdown shrimp followed by $V$. anguillarum injection. MjPIAS expression was knocked down in hemocytes at $48 \mathrm{~h}$ (Figure 4A). After the injection of $V$. anguillarum, the expression levels of AMPs were detected, and the results showed their expression levels were markedly increased compared with those in the control ( $d s G F P$ injection) in the hemocytes (Figures $4 \mathbf{B}, \mathbf{C}$ ). These results suggested that MjPIAS inhibits shrimp's antibacterial ability by negatively regulating the expression of AMPs controlled by the JAK/STAT pathway.

\section{PIAS Inhibits STAT Phosphorylation and Translocation}

To analyze the molecular mechanism whereby MjPIAS negatively regulates transcription of AMPs, the translocation and phosphorylation of STAT were detected by immunocytochemistry (Figure 5A) and western blotting (Figures 5B,C) using p-STAT antibody, and results showed that the phosphorylation of STAT was enhanced in hemocytes after $V$. anguillarum injection in the MjPIAS-silenced shrimp. The immunocytochemical assay using STAT antibody was also performed and result showed that STAT translocation into the nucleus increased in the MjPIAS-knockdown shrimp (Figure 5D). Meanwhile, we extracted the cytoplasmic and nuclear proteins from the hemocytes of PIAS-RNAi and control shrimp. The level of STAT in the cytoplasm and nucleus was detected using anti-STAT antibodies (Figures 5E,F). The results showed that much more STAT was detected in nucleus in the MjPIAS-RNAi shrimp comparing with control. These results suggested that MjPIAS negatively regulates STAT by inhibiting its translocation and phosphorylation.

\section{MjPIAS Interacts With the Native STAT of Shrimp}

In order to detect the interaction between MjPIAS and STAT, recombinant MjPIAS-RLD and STAT were purified from E. coli (Figure 5G). GST-pulldown was performed and there was no 
interaction was identified between the two recombinant proteins (Figure 5H).The recombinant MjPIAS-RLD was further used to pull down native STAT and result showed that MjPIAS-RLD could interact with native STAT from hemocytes of shrimp challenged by V. anguillarum (Figure 5I). These results suggested that MjPIAS could interact with activated STAT.

\section{DISCUSSION}

In this study, we identified MjPIAS, which was determined to negatively regulate STAT by analyzing the AMP transcription regulated by the JAK/STAT pathway in kuruma shrimp. Further study found that the molecular mechanism of the MjPIAS function comprised inhibiting STAT translocation and phosphorylation, and further inhibiting the expression of AMPs.

PIAS proteins play important regulatory role in cytokine signaling and immune system $(12,23)$. PIAS proteins act as transcriptional co-regulators of at least 60 different proteins, and either repress or activate their transcription. PIAS proteins interact with several transcription factors, such as STAT, NF$\kappa \mathrm{B}$, Jun, and $\mathrm{p} 53$, many of which are key transcription factors involved in the immune system. STAT is an important transcription factor in the JAK/STAT signaling pathway (2426). STAT is activated in the cytoplasm and forms dimers, resulting in its translocation to the cell nucleus where it combines with the corresponding cis-elements (27), activating downstream gene transcription. In shrimp, the JAK/STAT pathway can be directly activated by bacterial infection, which regulates the expression of AMPs, including ALF-A1, ALF-C1, ALF-C2, CruI1, and CruI-5 (21). Previous studies showed that PIAS could regulate the activity of the downstream genes by interaction with transcription factors or other transcriptional coactivators $(25,28,29)$. Based on its similar structural characteristics to PIAS proteins from other species, we explored whether MjPIAS could negatively regulate the shrimp JAK/STAT signaling pathway. Shrimp were challenged with $V$. anguillarum after the knockdown of MjPIAS, which resulted in increased expression of AMPs regulated by the JAK/STAT signaling pathway. In the bacterial clearance assay, the dsPIAS group showed stronger antibacterial ability. In addition, the survival experiment showed that the $d s P I A S$ group had a higher survival rate compared with that of the $d s G F P$ group. Taken together, the results indicated that PIAS is a negative regulator of the JAK/STAT pathway.

Several studies have shown that PIAS proteins play important roles in the regulation of the STAT signaling pathway. PIAS family members interact with various STATs in mammals, and the interaction requires cytokine stimulation (23). PIAS interacts with the dimeric form, but not the monomeric form, of STAT (30). In our pulldown study with MjPIAS with STAT, we found that recombinant $M j$ PIAS could not interact with recombinant STAT. However, recombinant MjPIAS could interact with native STAT from bacterial challenged shrimp (Figures 5H,I). These results suggest that MjPIAS interacts with dimeric form of STAT (activated STAT) in shrimp. The binding of PIAS to STAT results in inhibition of STAT-mediated gene activation by blocking the DNA binding activity of STAT (22), by recruiting other co-repressor molecules, such as HDACs, to inhibit transcription (31), and by promoting the sumoylation of a transcription factor (5), and by sequestering transcription factors in certain subnuclear structures that are enriched for corepressor complexes (32). Although the majority of reported interactions of PIAS proteins occurred with transcription factors or other proteins linked to nuclear regulation (33), there are examples of cytoplasmic interactions in which PIAS proteins are involved, such as interaction of septins with PIAS ortholog Siz1 in yeast bud neck (34), and functional interaction of PIAS3 with kainate receptor subunit, glutamate receptor-8 (35). In the present study, we found that the phosphorylation of STAT was enhanced in hemocytes after $V$. anguillarum injection in the MjPIAS-silenced shrimp by immunocytochemistry and western blotting using p-STAT antibody (Figures 5A-C). We also detected the level of STAT in the cytoplasm and nucleus of the hemocytes from PIAS-RNAi and control shrimp using anti-STAT antibodies, and found that much more STAT was detected in nucleus in the MjPIAS-RNAi shrimp comparing with control (Figures 5E,F). All the results revealed that MjPIAS might interact with STAT at cytoplasm and inhibit its translocation into the nucleus in addition to interaction with STAT in nucleus. These data suggested that MjPIAS negatively regulates STAT by inhibiting its translocation and phosphorylation. This is a new molecular mechanism for the negative regulation of transcription by PIAS, comprising inhibiting STAT phosphorylation and translocation into nucleus. Taken together with the results of our former study concerning the function of the JAK/STAT signal pathway (21), we hypothesized the possible mechanism of action of MjPIAS (Figure 6). The C-type lectin, MjCC-CL recognizes infected bacteria, and interacts with the receptor Dome, and activates JAK/STAT signal pathway. The transcription factor STAT is phosphorylated by JAK, and translocates into the nucleus, inducing the AMP expression. The pathway is subtly regulated by MjPIAS in cytoplasm and nucleus by interaction with STAT, and inhibiting STAT phosphorylation and translocation. To the best of our knowledge, this is the first report of the mechanism of PIAS-mediated gene regulation in the STAT signaling pathway in animals.

\section{AUTHOR CONTRIBUTIONS}

J-XW and G-JN designed the experiments and wrote the manuscript. G-JN performed the majority of the experiments and analyzed data. J-DX, W-JY, J-JS, M-CY, and Z-HH contributed experimental suggestions. X-FZ helped to design the experiments. All authors revised the manuscript.

\section{FUNDING}

This work was supported by the National Natural Science Foundation of China (Grant Nos. 31630084, 31472303, and 31130056), the Provincial Natural Science Foundation of Shandong Province, China (Grant No. ZR201709270079). 


\section{REFERENCES}

1. Schmidt D, Muller S. Members of the PIAS family act as SUMO ligases for c-Jun and p53 and repress p53 activity. Proc Natl Acad Sci USA. (2002) 99:2872-7. doi: 10.1073/pnas.052559499

2. Liu B, Liao J, Rao X, Kushner SA, Chung CD, Chang DD, et al. Inhibition of Stat1-mediated gene activation by PIAS1. Proc Natl Acad Sci USA. (1998) 95:10626-31. doi: 10.1073/pnas.95.18.10626

3. Suzuki R, Shindo H, Tase A, Kikuchi Y, Shimizu M, Yamazaki, T. Solution structures and DNA binding properties of the N-terminal SAP domains of SUMO E3 ligases from Saccharomyces cerevisiae and Oryza sativa. Proteins (2009) 75:336-47. doi: 10.1002/prot.22243

4. Duval D, Duval G, Kedinger C, Poch O, Boeuf, H. The 'PINIT' motif, of a newly identified conserved domain of the PIAS protein family, is essential for nuclear retention of PIAS3L. FEBS Lett. (2003) 554:111-8. doi: 10.1016/S0014-5793(03)01116-5

5. Jackson PK. A new RING for SUMO: wrestling transcriptional responses into nuclear bodies with PIAS family E3 SUMO ligases. Genes Dev. (2001) 15:3053-8. doi: 10.1101/gad.955501

6. Ke Y, Hunter MJ, Ng CA, Perry MD, Vandenberg JI. Role of the cytoplasmic N-terminal Cap and Per-Arnt-Sim (PAS) domain in trafficking and stabilization of Kv11.1 channels. J Biol Chem. (2014) 289:13782-91. doi: $10.1074 /$ jbc.M113.531277

7. Yun J, Nagai T, Furukawa-Hibi Y, Kuroda K, Kaibuchi K, Greenberg ME, et al. Neuronal Per Arnt Sim (PAS) domain protein 4 (NPAS4) regulates neurite outgrowth and phosphorylation of synapsin I. J Biol Chem. (2013) 288:2655-64. doi: 10.1074/jbc.M112.413310

8. Aravind L, Koonin EV. SAP - a putative DNA-binding motif involved in chromosomal organization. Trends Biochem Sci. (2000) 25:112-4. doi: 10.1016/S0968-0004(99)01537-6

9. Kotaja N, Karvonen U, Janne OA, Palvimo JJ. PIAS proteins modulate transcription factors by functioning as SUMO-1 ligases. Mol Cell Biol. (2002) 22:5222-34. doi: 10.1128/MCB.22.14.5222-5234.2002

10. Minty A, Dumont X, Kaghad M, Caput, D. Covalent modification of p73alpha by SUMO-1. Two-hybrid screening with p73 identifies novel SUMO-1interacting proteins and a SUMO-1 interaction motif. J Biol Chem. (2000) 275:36316-23. doi: 10.1074/jbc.M004293200

11. Tolkunova E, Malashicheva A, Parfenov VN, Sustmann C, Grosschedl R, Tomilin A. PIAS proteins as repressors of Oct4 function. J Mol Biol. (2007) 374:1200-12. doi: 10.1016/j.jmb.2007.09.081

12. Shuai K, Liu B. Regulation of gene-activation pathways by PIAS proteins in the immune system. Nat Rev Immunol. (2005) 5:593-605. doi: 10.1038/nri1667

13. Kato T Jr, Gotoh Y, Hoffmann A, Ono Y. Negative regulation of constitutive NF-kappaB and JNK signaling by PKN1-mediated phosphorylation of TRAF1. Genes Cells (2008) 13:509-20. doi: 10.1111/j.1365-2443.2008. 01182.x

14. Bao C, Li Y, Huan L, Zhang Y, Zhao F, Wang Q, et al. NF-kappaB signaling relieves negative regulation by miR-194 in hepatocellular carcinoma by suppressing the transcription factor HNF-1alpha. Sci Signal. (2015) 8:ra75. doi: 10.1126/scisignal.aaa8441

15. Hari KL, Cook KR, Karpen GH. The Drosophila Su(var)2-10 locus regulates chromosome structure and function and encodes a member of the PIAS protein family. Genes Dev. (2001) 15:1334-48. doi: 10.1101/gad.877901

16. Gronholm J, Ungureanu D, Vanhatupa S, Ramet M, Silvennoinen O. Sumoylation of Drosophila transcription factor STAT92E. J Innate Immun. (2010) 2:618-24. doi: 10.1159/000318676

17. Arora T, Liu B, He H, Kim J, Murphy TL, Murphy KM, et al. PIASx is a transcriptional co-repressor of signal transducer and activator of transcription 4. J Biol Chem. (2003) 278:21327-30. doi: 10.1074/jbc.C300119200

18. Takahashi Y. [Identification and function of ubiquitin-like protein SUMO E3 (PIAS family and RanBp2, Pc2)]. Seikagaku (2004) 76:381-4.

19. Okubo S, Hara F, Tsuchida Y, Shimotakahara S, Suzuki S, Hatanaka $\mathrm{H}$, et al. NMR structure of the N-terminal domain of SUMO ligase PIAS1 and its interaction with tumor suppressor p53 and A/T-rich DNA oligomers. J Biol Chem. (2004) 279:31455-61. doi: 10.1074/jbc.M4035 61200
20. Sun JJ, Lan JF, Xu JD, Niu GJ, Wang JX. Suppressor of cytokine signaling 2 (SOCS2) negatively regulates the expression of antimicrobial peptides by affecting the Stat transcriptional activity in shrimp Marsupenaeus japonicus. Fish Shellfish Immunol. (2016) 56:473-482. doi: 10.1016/j.fsi.2016.07.037

21. Sun JJ, Lan JF, Zhao XF, Vasta GR, Wang JX. Binding of a C-type lectin's coiled-coil domain to the Domeless receptor directly activates the JAK/STAT pathway in the shrimp immune response to bacterial infection. PLoS Pathog. (2017) 13:e1006626. doi: 10.1371/journal.ppat.1006626

22. Chung CD, Liao J, Liu B, Rao X, Jay P, Berta P, et al. Specific inhibition of Stat3 signal transduction by PIAS3. Science (1997) 278:1803-5. doi: $10.1126 /$ science.278.5344.1803

23. Shuai K. Regulation of cytokine signaling pathways by PIAS proteins. Cell Res. (2006) 16:196-202. doi: 10.1038/sj.cr.7310027

24. Di Napoli A, Jain P, Duranti E, Margolskee E, Arancio W, Facchetti F, et al. Targeted next generation sequencing of breast implant-associated anaplastic large cell lymphoma reveals mutations in JAK/STAT signalling pathway genes, TP53 and DNMT3A. Br J Haematol. (2018) 180:741-4. doi: 10.1111/bjh.14431

25. Nicolae A, Xi L, Pham TH, Pham TA, Navarro W, Meeker HG, et al. Mutations in the JAK/STAT and RAS signaling pathways are common in intestinal T-cell lymphomas. Leukemia (2016) 30:2245-7. doi: 10.1038/leu.2016.178

26. Yamahata $\mathrm{H}$, Osuka $\mathrm{K}$, Aoyama $\mathrm{T}$, Yasuda $\mathrm{M}$, Tokimura $\mathrm{H}$, Arita $\mathrm{K}$, et al. Expression of the JAK/STAT signaling pathway in the ligamentum flavum of patients with lumbar spinal canal stenosis. J Orthop Sci. (2017) 22:190-6. doi: $10.1016 /$ j.jos.2016.11.005

27. Gronholm J, Vanhatupa S, Ungureanu D, Valiaho J, Laitinen T, Valjakka J, et al. Structure-function analysis indicates that sumoylation modulates DNA-binding activity of STAT1. BMC Biochem. (2012) 13:20. doi: 10.1186/1471-2091-13-20

28. Zhang C, Yuan X, Yue L, Fu J, Luo L, Yin Z. PIASy interacts with p73alpha and regulates cell cycle in HEK293 cells. Cell Immunol. (2010) 263:235-40. doi: 10.1016/j.cellimm.2010.04.005

29. Li R, Pan Y, Shi DD, Zhang Y, Zhang J. PIAS1 negatively modulates virus triggered type I IFN signaling by blocking the DNA binding activity of IRF3. Antiviral Res. (2013) 100:546-54. doi: 10.1016/j.antiviral.2013.09.001

30. Liao J, Fu Y, Shuai K. Distinct roles of the NH2- and COOH-terminal domains of the protein inhibitor of activated signal transducer and activator of transcription (STAT) 1 (PIAS1) in cytokine-induced PIAS1-Stat1 interaction. Proc Natl Acad Sci USA. (2000) 97:5267-72. doi: 10.1073/pnas.97.10.5267

31. Liu B, Gross M, ten Hoeve J, Shuai KA transcriptional corepressor of Stat1 with an essential LXXLL signature motif. Proc Natl Acad Sci USA. (2001) 98:3203-7. doi: 10.1073/pnas.051489598

32. Sachdev S, Bruhn L, Sieber H, Pichler A, Melchior F, Grosschedl R. PIASy, a nuclear matrix-associated SUMO E3 ligase, represses LEF1 activity by sequestration into nuclear bodies. Genes Dev. (2001) 15:3088-103. doi: $10.1101 /$ gad. 944801

33. Rytinki MM, Kaikkonen S, Pehkonen P, Jaaskelainen T, Palvimo JJ. PIAS proteins: pleiotropic interactors associated with SUMO. Cell Mol Life Sci. (2009) 66:3029-41. doi: 10.1007/s00018-009-0061-z

34. Takahashi Y, Toh-e A, Kikuchi Y. A novel factor required for the SUMO1/Smt3 conjugation of yeast septins. Gene (2001) 275:223-31. doi: 10.1016/S0378-1119(01)00662-X

35. Martin S, Nishimune A, Mellor JR, Henley JM. SUMOylation regulates kainate-receptor-mediated synaptic transmission. Nature (2007) 447:321-5. doi: 10.1038/nature05736

Conflict of Interest Statement: The authors declare that the research was conducted in the absence of any commercial or financial relationships that could be construed as a potential conflict of interest.

Copyright (๐ $2018 \mathrm{Niu}, \mathrm{Xu}$, Yuan, Sun, Yang, He, Zhao and Wang. This is an open-access article distributed under the terms of the Creative Commons Attribution License (CC BY). The use, distribution or reproduction in other forums is permitted, provided the original author(s) and the copyright owner(s) are credited and that the original publication in this journal is cited, in accordance with accepted academic practice. No use, distribution or reproduction is permitted which does not comply with these terms. 